Review

\title{
Potential of exosomes as diagnostic biomarkers and therapeutic carriers for doxorubicin-induced cardiotoxicity
}

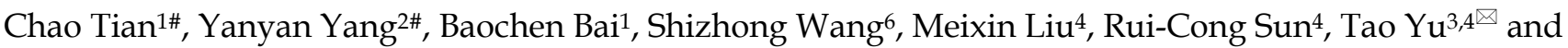 \\ Xian-ming $\mathrm{Chu}^{1,5 凶}$ \\ 1. Department of Cardiology, The Affiliated Hospital of Qingdao University, Qingdao 266000, China. \\ 2. Department of Immunology, Basic Medicine School, Qingdao University, Qingdao 266071, China. \\ 3. Institute for Translational Medicine, The Affiliated Hospital of Qingdao University, Qingdao 266021, China. \\ 4. Department of Cardiac Ultrasound, The Affiliated hospital of Qingdao University, Qingdao 266000, China. \\ 5. Department of Cardiology, The Affiliated Cardiovascular Hospital of Qingdao University, Qingdao 266032, China. \\ 6. Department of Cardiovascular Surgery, The Affiliated Cardiovascular Hospital of Qingdao University, Qingdao 266000, China. \\ \#These authors contributed equally to this paper. \\ $\square$ Corresponding authors: Tao Yu, PhD, Department of Cardiac Ultrasound, The Affiliated Hospital of Qingdao University, No. 16 Jiangsu Road, Qingdao \\ 266000, China; Institute for translational medicine, Basic Medicine School, Qingdao University, 38 Deng Zhou Road, Qingdao 266021, China. Tel.: \\ +86-532-82991791; fax: +86-532-82991791; E-mail: yutao0112@qdu.edu.cn. Xian-ming Chu, PhD, Department of Cardiology, the Affiliated Hospital of Qingdao \\ University, No. 59 Haier Road, Qingdao 266100, China. Tel.: +86-532-82913257; The Affiliated Cardiovascular Hospital of Qingdao University, No. \\ 5 Zhiquan Road, Qingdao 266071, China. Tel.: +86-532-66990020; fax: +86-532-66990020; E-mail: 18661801698@163.com.
}

(1) The author(s). This is an open access article distributed under the terms of the Creative Commons Attribution License (https://creativecommons.org/licenses/by/4.0/). See http://ivyspring.com/terms for full terms and conditions.

Received: 2021.01.28; Accepted: 2021.03.17; Published: 2021.03.27

\begin{abstract}
Doxorubicin (DOX) is a kind of representative anthracyclines. It has greatly prolonged lifespan of cancer patients. However, a long course of DOX chemotherapy could induce various forms of deaths of cardiomyocytes, such as apoptosis, pyroptosis and ferroptosis, contributing to varieties of cardiac complications called cardiotoxicity. It has become a major concern considering the large number of cancer patients' worldwide and increased survival rates after chemotherapy. Exosomes, a subgroup of extracellular vesicles (EVs), are secreted by nearly all cells and consist of lipid bilayers, nucleic acids and proteins. They can serve as mediators between intercellular communication via the transfer of bioactive molecules from secretory to recipient cells, modulating multiple pathophysiological processes. It has been proven that exosomes in body fluids can serve as biomarkers for doxorubicin-induced cardiotoxicity (DIC). Moreover, exosomes have attracted considerable attention because of their capacity as carriers of certain proteins, genetic materials (miRNA and IncRNA), and chemotherapeutic drugs to decrease the dosage of DOX and alleviate cardiotoxicity. This review briefly describes the characteristics of exosomes and highlights their clinical application potential as diagnostic biomarkers and drug delivery vehicles for DIC, thus providing a strategy for addressing it based on exosomes.
\end{abstract}

Key words: doxorubicin; cardiotoxicity; exosome; biomarker; delivery vehicles

\section{Introduction}

Globally, malignancies are a dominant cause of death and chemotherapy is an effective strategy. There are varieties of chemotherapeutic drugs, mainly including anthracycline, alkylating agent, antimetabolie antineoplastic agents, and antitumor antibiotics. Doxorubicin is a kind of typical anthracyclines, which belongs to the antitumor antibiotics. However, a long course of DOX chemotherapy exerts dose-dependent side effects on cardiomyocytes due to their vulnerability and low regenerative abilities $[1,2]$. These side effects were called cardiotoxicity.

The emergence of cardiotoxicities, such as arrhythmia, myelosuppression, cardiomyopathy, and congestive heart failure (CHF) limits clinical use of DOX [3], of which CHF is the most severe 
complication of long-term DOX chemotherapy [4]. Elucidating the mechanisms of DIC can unveil possible targets for solving these troubles. However, the exact mechanism remains unclear. The pivotal role of reactive oxygen species (ROS) or oxidative stress in cardiotoxicity has been highlighted [5-7]. They are involved in senescence [8] and various deaths of cardiomyocyte induced by DOX, including apoptosis [9], autophagy [10], necroptosis [11], pyroptosis [12], and ferroptosis [13]. Non-coding RNAs, which were previously considered as "evolutionary junk", were demonstrated to crucially participate in cardiovascular diseases (CVD) [14-21], particularly they exert significant influence during DIC [22]. Collectively, these findings explain the riddle of DIC to some extent.

Although accumulating studies have explored the means for DIC [23-26], dexrazoxane (DXR) remains the only FDA-approved drug for it [27]. And more powerful agents besides DXR need to be explored to deal with this troublesome problem. Moreover, early detection contributes to early intervention and improving prognosis. But it still lacks specific means for detecting DIC. Exosomes, secreted by most cells, lie in various body fluid and have been explored as biomarkers for many diseases [28]. Besides, they can transport bioactive molecules to regulate many physiological activities $[29,30]$ and have the potential as delivery vehicles of drugs and regulatory molecules for CVD [31], tumors [32], and inflammation [33]. Notably, exosomes can protect their cargos from degradation due to their double-layered membrane, prolonging its half-life in circulation and enhancing its therapeutic functions.

In this review, we point out the possibility of exosomes as biomarkers and delivery vehicles for diagnosis and therapy for DIC. We hope that with deepening cognition to exosomes' potential in DIC, they can come into clinical practice in the near future.

\section{Definition, biogenesis, and structure of exosomes}

Secreted by membrane vesicles, extracellular vesicles (EVs) are highly heterogeneous and traditionally divided into three categories based on size: apoptosomes, microvesicles, and exosomes. Exosomes, derived from the endosomal membrane through endocytosis, range from 30 to $150 \mathrm{~nm}[34,35]$. They are present in almost all body fluids $[36,37]$. The formation of exosomes undergoes double invagination. First, the plasma membrane invaginates to form a cup-shaped structure called the earlysorting endosome (ESE) with the assistance of Golgi complex. The endoplasmic reticulum also participates in this process by providing the content. Next, the endosomal membrane undergoes secondary invagination, inducing ESEs to shape intracellular multi-vesicles bodies (MVBs). When the MVBs merge with the cell membrane, exosomes finally take shape through exocytosis [38].

The exosomes are formed by a phospholipid bilayer and bioactive cargos such as nucleic acids, including mRNAs, microRNAs (miRNAs) [39], circular RNAs (circRNAs) [40], long noncoding RNAs (lncRNAs) [41], Piwi-interacting RNAs (piRNAs) [42], double-stranded DNAs (dsDNA) [43], and tRNA-derived small RNAs (tsRNAs) [44], lipids, and proteins. Of these contained nucleic acids, piRNAs are novel compared with others and have been discussed its role in CVD [45]. The lipids of exosomes, including cholesterols, ceramides, sphingomyelins, phosphatidylglycerols, and phosphatidylserine [46, 47], are largely derived from the parental cell and the Golgi complex. The proteins of exosomes include a series of tetraspanins, such as CD9, CD63, and CD81, some adhesion molecules and integrins, modulating signal transduction between cell-cell communication, of which the tetraspanins family, TSG101 and Alix has been regarded as common biomarkers for exosomes (Figure 1).

\section{Exosomes as diagnosis biomarkers for DIC}

Due to the non-selective effects of DOX on cells, cardiotoxicity is unavoidable. Clinicians usually monitor cardiotoxicity by atypical symptoms (nausea, vomiting, and fever) and typical symptoms (hypotension, thrombosis, arrhythmia, myocarditis, and pericarditis). They also utilize techniques, such as echocardiography, multigated acquisition scanning (MUGA) [48, 49], and cardiac magnetic resonance (CMR) [50] to assess the heart injury induced by DOX. MUGA is the "gold standard" for supervising anthracycline-related heart damage [51], but its use is limited due to the risk associated with the radiation exposure. Advantageously, CMR identifies microstructure heart lesions, like diffuse fibrosis and anthracycline-related myocardial fibrosis [52-54], however, patients with pacemakers or other metals in body are excluded, limiting its use in clinic. In general, the evaluation of LVEF is not a sensitive tool because few changes occur in systolic function until significant myocardial damage has taken place, while MUGA is not safe and CMR is not universally applicable.

Cardiac troponins are routinely regarded as sensitive biomarkers for diagnosing acute myocardial infarction (AMI) [55]. Also, elevated serum troponins are observed in a wide spectrum of cardiac injuries, such as cardiac trauma, CHF, pulmonary embolism, 
and chemotherapy-related cardiac toxicity [56]. Some clinical studies have confirmed that troponins can be used to assess the cardiotoxicity induced by chemotherapy, specially trastuzumab and several tyrosine kinase inhibitors [57-59]. Similarly, natriuretic peptide (NP) including brain natriuretic peptide (BNP), atrial natriuretic peptide (ANP), and their N-terminal counterparts (NT-pro BNP and NT-pro ANP), used to be considered as biomarkers for heart failure, have been explored as predictors of anticancer drug-induced cardiotoxicity [60-62]. Both troponins and NP family can reveal heart damage regardless of various causes, but they not specific enough for DIC. Here, we introduce exosomes as promising, specific, and stable biomarkers for early cardiotoxicity induced by DOX.

\section{Exosomal miRNAs as biomarkers for DIC}

Studies have confirmed that miRNAs in circulation could be markers for DIC [63]. Here, we focus on exploring the potential of exosomal miRNAs for diagnosing DIC.

In a trial, EV-derived miRNAs in serum were found to express differently after single-DOX chemotherapy in dogs model of sarcoma compared with the initial. In detail, exosomal miR-107 and miR-146a were greatly downregulated, while exosomal miR-502 was upregulated. The changes in the pattern of exosomal miRNAs were more persistent compared to $\mathrm{CTnI}$ in serum [64]. This results uncovered that exosomal-502 may be a damage marker for DIC, but it still needs to be validated following larger samples.

\section{Exosomal proteins as biomarkers for DIC}

Studies have confirmed that exosomes contain many proteins related to cancers. And they could serve as biomarkers for pancreatic cancer [65], non-small cell lung cancer (NSCLC) [66], and gastric cancer (GC) [67]. Besides, Chontida et al. reported that PYGB (brain/heart glycogen phosphorylase) in EVs, released from DOX-injured cardiomyocytes, could be a sensitive and early biomarker for DIC, for it started to elevate before troponin in the DOX-treated group [68]. More proteins in exosomes or EVs await for further exploration as biomarkers for DIC (The part of exosomes functioning as biomarkers were shown in Table 1).

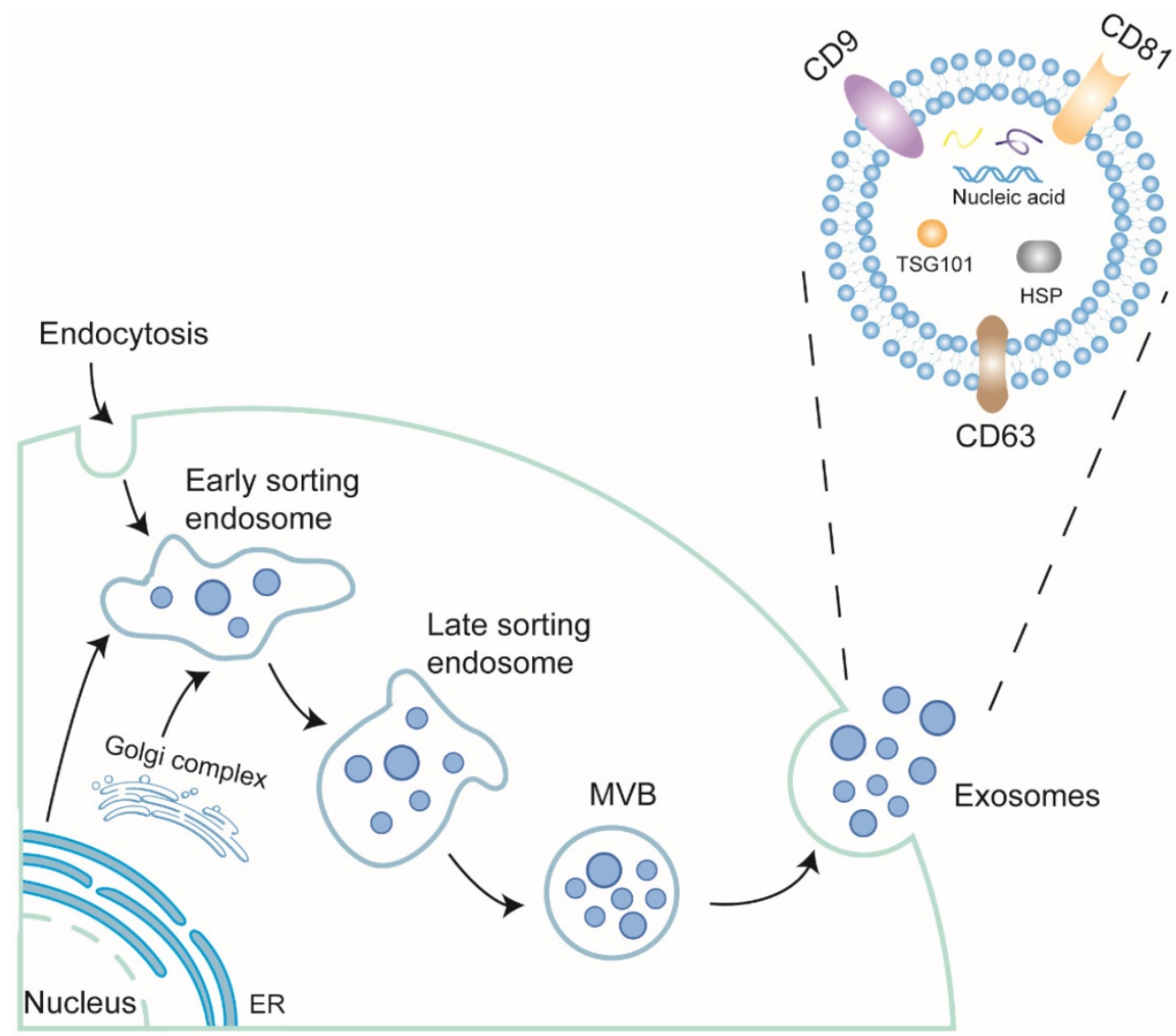

Figure 1. The biogenesis and structure of exosomes. The plasma membrane firstly invaginates into early sorting endosome (ESE) with the assistance of Golgi complex and endoplasmic reticulum. Then, ESE can generate late sorting endosome (LSE). The LSE undergoes second invagination and forms multivesicular body (MVB). MVB contains a structure called Intraluminal vesicles (ILV), which will be modified further. When MVB fuses with plasma membrane, ILVs will be released. At the time, ILV become exosomes. Exosomes are comprised of lipid bilayer and contents. The contents include nucleic acids (RNAs and DNAs), lipids and proteins. Some proteins are located on the membrane as receptor signals or receptors, some transverse the bilayer, like tetraspanin family, as hallmarks of exosomes, while some are in the exosomes, like TSG 101, Alix, also function as hallmarks or play some certain roles. 
Exosomes function as delivery vehicles

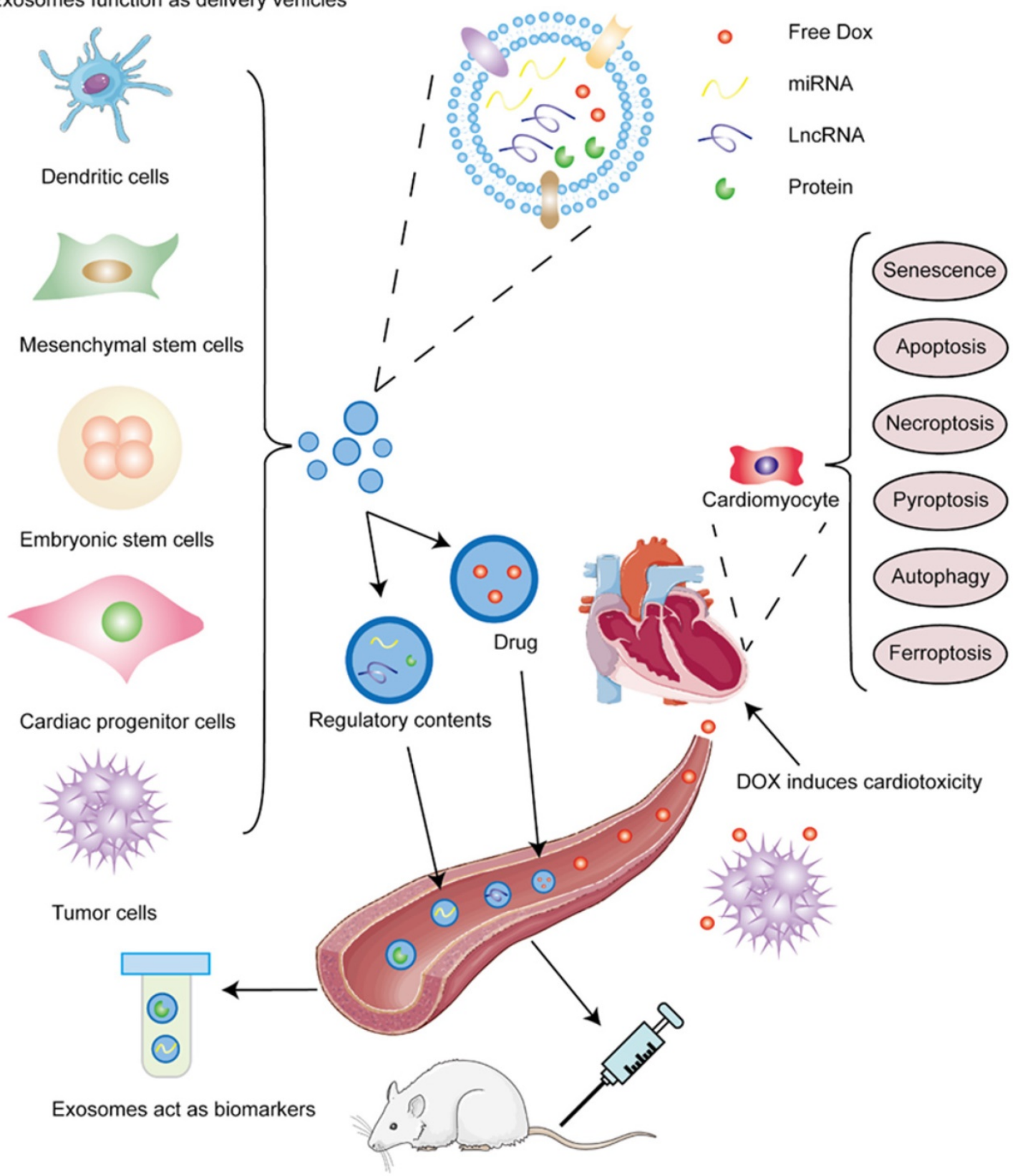

Figure 2. Different sources of exosomes and contained cargos alleviate DIC. DOX induces cardiotoxicity. DOX not only kill tumor cells through circulation, it but also damages cardiomyocytes at the same time and induces senescence and various death forms of cardiac cells, such as apoptosis, necroptosis, autophagy, pyroptosis, and ferroptosis. Exosomes act as biomarkers for DIC. Exosomes are comprised of phospholipid bilayer and contents, including proteins, which are also inserted into bilayer, and nucleic acids. MiRNAs and some proteins in exosomes can be used to forecast the emergence and prognosis of DOX-induced cardiotoxicity. Exosomes function as delivery vehicles for DIC. Varieties of cells, such as dendritic cells, mesenchymal stem cells, embryonic stem cells, cardiac progenitor cells, and tumor cells can secret exosomes or transfer contained miRNAs and IncRNAs to alleviate DOX-induced apoptosis and pyroptosis, decreasing DIC.

Table 1. Exosomes/EVs as biomarkers for diagnosing DIC

\begin{tabular}{llllll}
\hline $\begin{array}{l}\text { Parts of } \\
\text { exosomes/EVs }\end{array}$ & Components & Model & Distribution & Significance & Ref. \\
\hline miRNAs & miR-502 & dog & serum & $\begin{array}{l}\text { Uncovered the } \\
\text { potential of } \\
\text { miRNAs as } \\
\text { biomarkers }\end{array}$ & \\
& PYGB & mouse & serum & $\begin{array}{l}\text { Detected heart } \\
\text { injury early and } \\
\text { sensitively }\end{array}$ \\
protein & [68] & \\
& & & & & \\
\hline
\end{tabular}

\section{Exosomes as therapeutic delivery vehicles}

The superior characteristics of nonimmunogenicity and high-capacity make exosomes ideal vehicles for chemotherapeutic drugs and genetic regulators. In this section, we introduce cells that produce exosomes and discuss the bioactive contents delivered by them to alleviate cardiotoxicity. Summaries are shown in Table 2 and Table 3. Schematic presentation is shown in Figure 2. 
Table 2. Exosomes released by different cells alleviate DIC

\begin{tabular}{|c|c|c|c|}
\hline Parent cell & Recipient cell & Effects & Ref. \\
\hline \multirow{2}{*}{$\begin{array}{l}\text { Embryonic stem cell } \\
\text { (ESC) }\end{array}$} & \multirow[t]{2}{*}{ H9C2 cells } & Inhibit pyroptosis & [69] \\
\hline & & Inhibit pyroptosis & [70] \\
\hline $\begin{array}{l}\text { Adipose-mesenchymal } \\
\text { stem cell (MSC) }\end{array}$ & Cardiomyocyte & $\begin{array}{l}\text { Protect cardiomyocyte from } \\
\text { senescence }\end{array}$ & [71] \\
\hline $\begin{array}{l}\text { Cardiac progenitor cell } \\
\text { (CPC) }\end{array}$ & Cardiomyocyte & $\begin{array}{l}\text { Repress oxidative stress and } \\
\text { decrease myocardial fibrosis }\end{array}$ & [72] \\
\hline Tumor cell & Tumor cell & Target tumor selectively & [73] \\
\hline \multirow[t]{2}{*}{ Dendritic cell (DC) } & Tumor cell & Inhibit tumor growth & [74] \\
\hline & T cell & $\begin{array}{l}\text { Facilitate } \mathrm{T} \text { cell response to } \\
\text { cancer }\end{array}$ & [75] \\
\hline
\end{tabular}

\section{Exosomes derived from different cells to alleviate DIC}

Cell transplantation has been explored to exert repair functions through injection, but its application is limited for low survival rate and immunogenicity in vivo. Increasing evidence has shown that exogenous cell transplantation play therapeutic function through paracrine of EVs, since it is reversed by exosome inhibitor, GW4869 $[76,77]$. Thus, experts have pointed out that EV/exosomes-based injection could replace cell transplantation, which retain the therapeutic effects and are more safe and easy to store compared with cell transplantation.

\section{Embryonic stem cell-derived exosomes}

As is mentioned before, pyroptosis is a kind of cardiomyocyte death induced by DOX. This death is characterized by the release of vast pro-inflammatory factors and participates in the development of infectious diseases, neurological disorders and cardiovascular diseases (CVD). NLRP3, which has been validated its function in endothelial dysfunction [78], plays a key role in pyroptosis and is considered as a marker for it. Exosomes derived from embryonic stem cells were demonstrated to inhibit DOX-induced pyroptosis with the decrease of NLRP3 and other pyroptosis-related indexes [69]. Similarly, Dinender and his colleagues also found that this kind of exosomes could repress the expression of some pyroptosis markers and reduce cardiac hypertrophy, improving heart functions [70]. These studies verified the potential of embryonic stem cells as reliable sources of exosomes for attenuating DOX-induced pyroptosis.

\section{Mesenchymal stem cell (MSC)-derived exosomes}

Mesenchymal stem cells (MSCs) mainly derive from bone marrow and adipose tissues and have the potential of proliferating and differentiating into multiple cell types. Researchers have used mesenchymal stem cells (MSCs) as common, efficient, and productive sources of exosomes, for they possess the capacity to promote osteogenesis [79], alleviate inflammation [80], treat cerebrovascular diseases [81, 82], and heart diseases [83, 84]. There was a comparison between the therapeutic effects of human adipose-derived mesenchymal stem cells (AT-MSCs) and bone marrow mesenchymal stem cells (BM-MSCs) for DIC on rats, the results displayed that they two were equal in alleviating cytotoxicity through decreasing inflammation responses and fibrosis [85]. Moreover, hypoxia, used to be considered as a detrimental factor for it can induce ischemia-reperfusion (I/R) injury, has also intriguingly improved biological activity and showed better therapeutic functions. For instance, human adipose-derived mesenchymal stem cells (AT-MSCs) were treated with hypoxia and stimulated the secretion of exosome ${ }^{\text {Hypoxia, }}$ exosome ${ }^{\text {Hypoxia }}$ showed superiority in protecting cardiomyocytes from senescence induced by DOX [71]. The indistinguishably therapeutic effects of AT-MSC and BM-MSC implied that the secretion of exosomes was the common characteristic of MSCs, and the pretreatment of hypoxia could achieve better effects.

\section{Cardiac progenitor cell (CPC)-derived exosomes}

Exosomes derived from CPCs have been proven to be cardioprotective for myocardial infarction (MI) and ischemia/reperfusion (I/R) in vitro and in vivo $[76,77]$. In another study, exosomes derived from CPCs were isolated from conditioned medium and pretreated neonatal rat ventricular myocytes, then they were exposed to Doxorubicin and trastuzumab (DOX/Trz) in succession. The results displayed that the exosomes ameliorated DOX-/Trz-induced cardiotoxicity through repressing inflammatory responses and decreasing myocardial fibrosis. Notably, exosomal miR-146-5p partly mediated the cardioprotection [72]. This result was similar to a previous study, which found that miR-146a in exosomes inhibited oxidative stress-induced apoptosis of cardiomyocytes and decreased the size of in farction [77]. MiR-146 present in exosomes have exhibited preeminent regeneration ability.

Table 3. Different cargos released by exosomes regulate DIC

\begin{tabular}{lllll}
\hline Cargos & Classfications & Secreted cell and detailed cargo & Recipient cell & Effects \\
\hline DOX & NA & NA & Breast cancer cell & Increase DOX efficacy of killing tumors \\
$\begin{array}{l}\text { Non-coding } \\
\text { RNAs }\end{array}$ & miRNAs & $\begin{array}{l}\text { Myeloid-derived suppressor cells } \\
\text { (MDSC)-derived miR-126 }\end{array}$ & Tumor cell & Inhibition of exosomal miR-126 induce the \\
& $\begin{array}{l}\text { Monocytes-derived miR-159 } \\
\text { Adipose-MSC-derived miR-199a }\end{array}$ & $\begin{array}{l}\text { Breast cancer cell } \\
\text { death of MDSC }\end{array}$ & $\begin{array}{l}\text { Lead to cancer cell death } \\
\text { [107] }\end{array}$ \\
\hline
\end{tabular}




\begin{tabular}{|c|c|c|c|c|c|}
\hline Cargos & Classfications & Secreted cell and detailed cargo & Recipient cell & Effects & Ref. \\
\hline & & Breast cancer tissue-derived miR-770 & $\begin{array}{l}\text { Triple negative breast cancer } \\
\text { (TNBC) }\end{array}$ & Induce the apoptosis of tumor cells & [109] \\
\hline & & miR-501 & Gastric cancer(GC) & Inhibit the apoptosis of GC & [110] \\
\hline & lncRNAs & Breast cancer-derived lncRNA H19 & Breast cancer cell & Resist the apoptosis of cancer cells & [113] \\
\hline & & $\begin{array}{l}\text { Mesenchymal stem cell (MSC)-derived } \\
\text { lncRNA MALAT1 }\end{array}$ & Cardiomyocyte & Protect cardiomyocyte from senescence & [71] \\
\hline Protein & CD47 & Tumor cell & Tumor cell & $\begin{array}{l}\text { Anti-CD47enhances DOX-induced tumor } \\
\text { death synergistically }\end{array}$ & [115] \\
\hline
\end{tabular}

\section{Tumor cell-derived exosomes}

Usually, experts explore the possibility of making exosomes target tumors more selectively, actually, tumor itself is a source of exosomes. Previous studies have confirmed the "homing behavior" of stem cells. This behavior could guide stem cells to reach the impaired cells or organs and repair them. If tumor cells have similar behavior, exosomes derived from tumor cells may kill themselves locally without distant movement. Recently, $\mathrm{Li}$ and co-workers discovered that tumor-derived exosomes preferentially fuse with parent cancer cells in vitro, this cancer-homing behavior similar to the Trojan horse enables such exosomes to be better therapeutic agent to treat cancer and enhance the therapeutic drug retention [73]. However, it remains an obstacle that exosomes can be rapidly swallowed up by the mononuclear phagocyte system, this characteristics hindered them to be delivered into tumor. Thus, Wan et al. designed a two-step exosome delivery strategy, in short, they knock down endocytosis-related gene, $\mathrm{Cltc}$, in exosomes and successfully blocked the uptake of exosomes from MPS, facilitating exosomes to distribute more efficiently [86]. However, tumor-derived exosomes also promote the metastasis of tumors. Exosomes play the role of immune activation and suppression at the same time. The activation effect mainly depend on its role of antigen presentation, while the suppression effect mainly depend on the ligand they carry [87]. So the effects of various ligands in exosomes should be identified so as to achieve therapeutic goal and avoid tumor progression.

\section{Dendritic cell (DC)-derived exosomes}

Dendritic cells (DCs) are the professional antigen presenting cells. They secrete EVs to play a significant role in CVDs [88-90], tumors [91-93], myasthenia gravis [94], and transplant organ research [95].

Natural exosomes are regarded as less immunogenic and toxic, they are not always therapeutic. For example, immature dendritic cells (imDCs) can produce exosomes, but they could not target tumor selectively, when they were engineered to express a special exosomal membrane protein called Lamp2b, they could deliver cargo of DOX to tumor selectively and inhibit their growth without obvious cardiotoxicity, which is of great potential for clinical application [74]. Recently, Phung et al. developed an anti-cancer strategy based on DC-derived exosomes: anti-CTLA-4 antibody was anchored in lipids of exosomes of DCs, which guide the exosomes towards $\mathrm{T}$ cells, in addition, they endowed the exosomes with ability to block checkpoint, both enhancing the $\mathrm{T}$ cell response to cancer cells synergistically [75]. Stimulating cancer-specific $\mathrm{T}$ cells to response is expected to become a replacement strategy for cancer vaccine and can also decrease the usage of DOX, thus ameliorating cardiotoxicity.

\section{Delivery vehicles of different cargos}

\section{Delivery of DOX}

As is mentioned above, the non-targeted damage has limited the use of DOX in cancer patients. Hence, it is necessary to find a strategy to make the drug more tumor-specific. Increasing studies have proven that exosomes can be constructed to deliver DOX to treat cancers and they showed better loading capability and splendid efficacy compared to the traditional form of DOX $[96,97]$. In order to compare the cardiotoxicity between DOX encapsulated in exosomes (exoDOX) and free form, tumor volume was measured after treatment of them to assess the killing effect, the results showed that exoDOX was potent as free DOX and nontoxic meanwhile [98]. Similarly, exosomes isolated from breast cancer cells and ovarian cancer cell lines in the mouse models, respectively, were loaded with DOX, they also maintained the efficacy of DOX without enhancing the cardiotoxicity of DOX [99]. Exosomes have become common delivery vehicles of DOX to target various cancers and receive better therapeutic effects than free DOX.

\section{Delivery of regulatory genes}

\section{Delivery of miRNAs}

MicroRNAs, 19 22 nucleotides, can inhibit mRNA translation or promote degradation, thus negatively regulating expression of genes [100]. They participate in the occurrence and development of heart diseases and regulate cardiac function, such as 
heart morphogenesis and growth, myocardium contraction, and conductance of electrical signals, thus imparting therapeutic effects [101-103].

Since DOX induces cardiomyocytes death and cardiac atrophy, promoting the proliferation of cardiomyocyte is an approach to reversing damage [104]. Researchers demonstrated that cardiac fibroblast-derived exosomes transported miR-21 to mediate the hypertrophy of cardiomyocyte and they were potential therapeutic candidates for DOX-induced atrophy [105]. Chemoresistance not only increase the cardiotoxicity as the dosage accumulates, but also cause chronic inflammation. Relieving the inflammation may be conducive to solving this problem. Specially, chemoresistance is more common to occur during or after breast cancer. So, addressing breast-related cardiotoxicity is of great significance. Deng and colleagues identified that DOX treatment in mouse model of breast cancer resulted in the production of myeloid-derived suppressor cells (MDSCs), which secreted exosomal miR-126 to promote lung metastasis and reverse DOX-induced death of MDSC, developing inhibitors for exosomal miR-126 secreted by MDSCs may be a target for solving DOX-resistance in breast cancer [106].

Triple-negative breast cancer (TNBC) refers the Results of immunohistochemical examination of estrogen receptor, progesterone receptor and protooncogene (Her 2) are all negative. Its prognosis is poor in breast cancer and deserves attention. Gong and coworkers identified that a kind of exosomes could express disintegrin and metalloproteinase 15 on the membrane (A15-Exos), which can deliver DOX and miR-159 modified by cholesterol to TNBC cells at the time, exerting synergetic therapy of anti-cancer through silencing TCF-7 without adverse effects [107]. For addressing chemo-resistance in hepatocellular carcinoma, Lou et al. isolated exosomes from adipose tissues-derived mesenchymal stem cells (AMSCs) and constructed miR-199a-modified AMSCs (AMSC-199a) through lentivirus injection of miR-199a. They found that AMSC-Exo-199a administration effectively sensitized HCC to DOX by targeting $m$ TOR pathway [108]. Treatment failure of TNBC in clinical practice is mostly due to chemo-resistance and metastasis. Researchers found that miR-770 in exosomes derived from THP-1 cells can decrease chemo-resistance of DOX via promoting apoptosis of tumor cells in TNBC, and miR-770 was elevated in tissues-sensitive to chemotherapy evidenced this result clinically, displaying that exosomal miR-770 may be a therapeutic target or prognostic indicator for TNBC [109].

For other chemo-resistant cancers, researchers found that miR-501 were enriched in exosomes derived from DOX-resistant cell line of gastric cancer, it plays a role in inhibiting the apoptosis of gastric cancer cell and promoting it to proliferate and migrate through Akt pathway [110].

The role of miRNAs are more studied in exosomes for its abundance in exosomes compared with other nucleic acids. But other nucleic acids should not be ignored, they may be more crucial in modulation than miRNAs though less.

\section{Delivery of IncRNAs}

Long-noncoding RNAs (lncRNAs), length exceeding $200 \mathrm{nt}$, are a subset of non-coding RNAs and modulate transcription and expression of genes from short- and distant range. Increasing evidence points out that lncRNAs are involved in cardiomyocyte proliferation, cardiac repairing and senescence $[111,112]$.

Recently, lncRNA H19 contained in exosomes were found to regulate DOX resistance of breast cancer. The treatment of exosomal H19 from DOX-resistant breast cells sensitive cells increased chemoresistance, while this phenomenon could be reversed by downregulating H19. This implied that exosomal lncRNAs could affect DOX resistance and act as a therapeutic target [113]. As is mentioned above, exosomes generated from MSCs could inhibit DOX-induced cardiac senescence, this cardioprotective effect was mediated by overexpressing

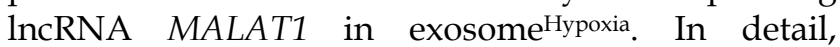
MALAT1 sponged microRNA-92a-3p, and the binding of them activated ATG4a, improving mitochondrial metabolism and thus partially playing a cardioprotective role in DOX-induced cardiac lesions [71].

\section{Exosomal proteins modulating DIC}

Proteins are the inherent structure of exosomes. And certain proteins of exosomes can mediate communication between exosome-secreting and recipient cells. They may have an effect on the development and treatment of DIC.

Recently, Tania et al. attested that EVs membranes contain a special protein called gap junction protein Connexin 43 (CX43), a variety of channel of exosome. It could facilitate the contents of EVs to enter into recipient cells [114]. These traits may enable this protein to aid EV to aim at the target more selectively. Recognition of checkpoints for killing cancer cells by immunotherapy has attracted much attention. CD47, a cell surface glycoprotein, is a novel checkpoint commonly express on the surface of cancer cells. Tumor cells secrete exosomes highly enriched CD47, which promoted metastasis and facilitated a microenvironment for tumor progression. Studies have demonstrated that anti-CD47 can achieve better 


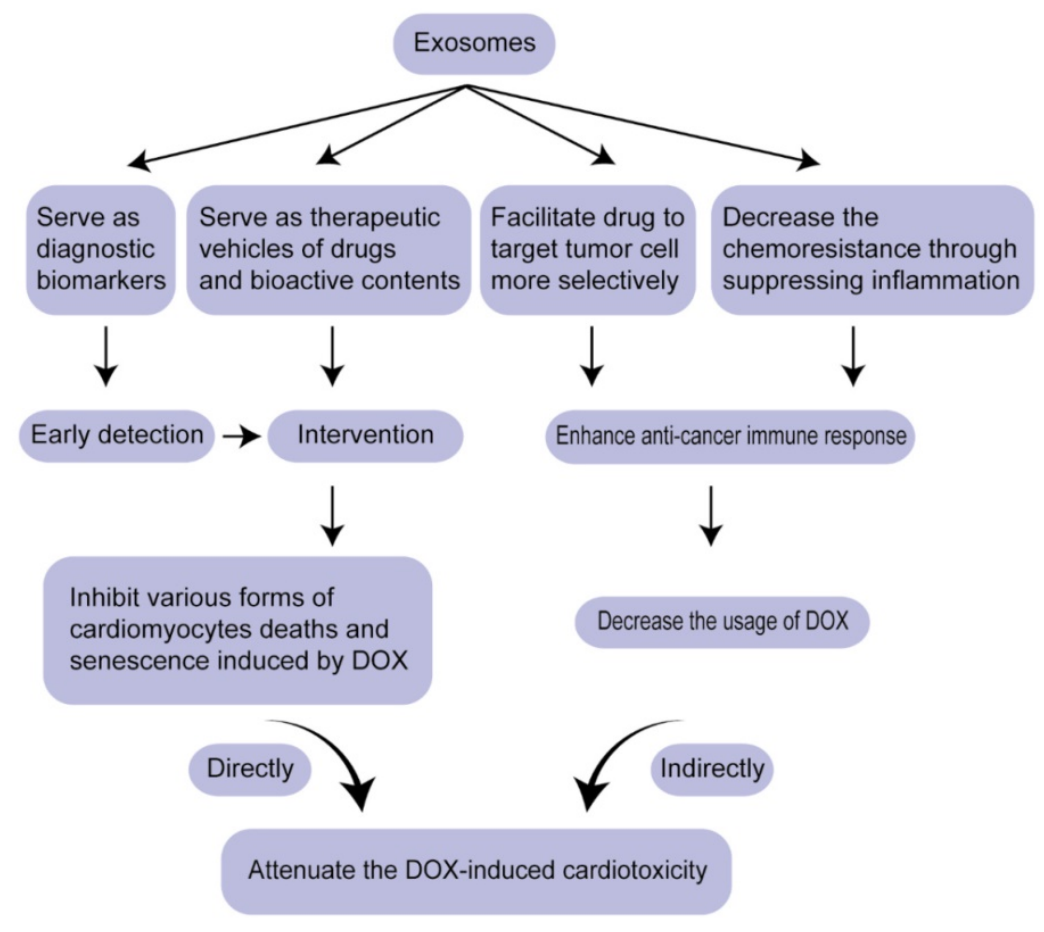

Figure 3. Overview of the strategy for attenuating DIC based on exosomes. contained in exosomes needs to be explored further as reliable biomarkers for cardiac toxicity. In the aspect of therapeutic vehicles, exosomes as anti-tumor vaccination have come into phase I trial. Exosomes can be expected as a replacement of anti-tumor vaccination to enhance the identification and killing response mediated by immune cells, thus decreasing the dosage of DOX and attenuating cardiotoxicity.

There are still some problems. First, means of enriching exosomes require further improvements. Second, more tools need to be developed to facilitate exosomes to target tumor more selectively besides CRISPR/Cas9 system [117]. Third, how to make exosomes stably exist in circulation is also a problem. Recently, researchers have developed a method detecting breast cancer through amplifying mRNAs in urine [118], which evoke researchers to find more available biomarkers for DIC in other body fluids.

therapeutic effects [115]. It has been reported that there was mutual effect between CD47 and SIRPa, a signal protein on phagocytic cells. The binding of them prevented phagocytic cells swallowing tumor cells. However, exosomes harbored with SIRPa variants (SIRPa-exosomes) could break the association between CD47 and SIRPa and relieve the resistance of phagocytic cell, which provides a strategy for enhancing immune response to cancers based on exosomal proteins [116].

\section{Conclusions and Future Perspectives}

CVDs and cancers are the top two fatal diseases worldwide. Traditionally, they are viewed as independent diseases. With the wide application of chemotherapy and the emergence of heart symptoms, accumulating attention was attracted on how to mitigate heart reverse effects, cardiotoxicity, without weakening the potency of drugs, contributing to the birth of a novel discipline-CardiOncology. Exosome, a kind of liquid biopsy, mitigate DIC via two pathways: serving as diagnostic biomarkers for early detection and therapeutic vehicles for drugs or regulatory molecules (nucleic acids and proteins), which not only regulate various forms of cardiomyocyte deaths induced by DOX and alleviate cardiac injuries directly, but also modulate chemo-resistance of cancer cells, thus decreasing the cardiotoxicity indirectly (Figure 3). miRNAs and proteins in exosomes as biomarkers for DIC have been discussed, the potential of lncRNAs, circRNAs and other nucleic acids
Collectively, due to their advantageous features discussed in this review, exosomes will be preeminent in the aspects of diagnosis and therapy for DIC in the near future with the development of proteomics, genomics, and high-throughput sequencing technology. Combining the superior characteristics of exosomes and nanoparticles designed for capturing biomarkers or delivering mRNA and siRNA [119], will bring favorable diagnostic and therapeutic effects.

\section{Acknowledgments}

All authors contributed to the study conception and design. Material preparation, data collection and analysis were performed by Chao Tian, Yanyan Yang, Baochen Bai and Shizhong Wang. The first draft of the manuscript was written by Chao Tian. And Tao Yu, Meixin Liu, Rui-Cong Sun and Xian-ming Chu helped with the final revision of the article. All authors read and approved the final manuscript.

\section{Funding}

This work was supported by The National Natural Science Foundation of China (grant no. 81870331, 31701208), The Natural Science Foundation of Shandong Province (grant no. ZR2020MH016), The Project of Shandong Province Higher Educational Science and Technology Program (No. J18KA285), and Cardiovascular multidisciplinary integrated thinking Research Fund scientific research public welfare project (grant no. Z-2016-23-2001-31). 


\section{Competing Interests}

The authors have declared that no competing interest exists.

\section{References}

1. Young RC, Ozols RF, Myers CE: The anthracycline antineoplastic drugs. The New England journal of medicine. 1981; 305(3):139-153.

2. Blum RH, Carter SK: Adriamycin. A new anticancer drug with significant clinical activity. Ann Intern Med 1974; 80(2):249-259.

3. Räsänen M, Degerman J, Nissinen TA, Miinalainen I, Kerkelä R, Siltanen A, Backman JT, Mervaala E, Hulmi JJ, Kivelä R et al: VEGF-B gene therapy inhibits doxorubicin-induced cardiotoxicity by endothelial protection. Proceedings of the National Academy of Sciences of the United States of America. 2016; 113(46):13144-13149.

4. Wen J, Zhang L, Wang J, Wang J, Wang L, Wang R, Li R, Liu H, Wei S, Li H et al: Therapeutic effects of higenamine combined with [6]-gingerol on chronic heart failure induced by doxorubicin via ameliorating mitochondrial function. Journal of cellular and molecular medicine. 2020; 24(7):4036-4050.

5. Wu YZ, Zhang L, Wu ZX, Shan TT, Xiong C: Berberine Ameliorates Doxorubicin-Induced Cardiotoxicity via a SIRT1/p66Shc-Mediated Pathway. Oxidative medicine and cellular longevity. 2019; 2019:2150394.

6. Hu C, Zhang X, Wei W, Zhang N, Wu H, Ma Z, Li L, Deng W, Tang Q: Matrine attenuates oxidative stress and cardiomyocyte apoptosis in doxorubicin-induced cardiotoxicity via maintaining AMPKa/UCP2 pathway. Acta pharmaceutica Sinica. B 2019; 9(4):690-701.

7. Zhao L, Tao X, Qi Y, Xu L, Yin L, Peng J: Protective effect of dioscin against doxorubicin-induced cardiotoxicity via adjusting microRNA-140-5pmediated myocardial oxidative stress. Redox biology. 2018; 16:189-198.

8. Maejima $\mathrm{Y}$, Adachi $\mathrm{S}$, Ito $\mathrm{H}$, Hirao $\mathrm{K}$, Isobe $\mathrm{M}$ : Induction of premature senescence in cardiomyocytes by doxorubicin as a novel mechanism of myocardial damage. Aging cell. 2008; 7(2):125-136.

9. Arola OJ, Saraste A, Pulkki K, Kallajoki M, Parvinen M, Voipio-Pulkki LM: Acute doxorubicin cardiotoxicity involves cardiomyocyte apoptosis. Cancer Res Treat. 2000; 60(7):1789-1792.

10. Lu L, Wu W, Yan J, Li X, Yu H, Yu X: Adriamycin-induced autophagic cardiomyocyte death plays a pathogenic role in a rat model of heart failure. Int J Cardiol. 2009; 134(1):82-90.

11. Zhang T, Zhang Y, Cui M, Jin L, Wang Y, Lv F, Liu Y, Zheng W, Shang H, Zhang J et al: CaMKII is a RIP3 substrate mediating ischemia- and oxidative stress-induced myocardial necroptosis. Nat Med. 2016; 22(2):175-182.

12. Wang Y, Gao W, Shi X, Ding J, Liu W, He H, Wang K, Shao F: Chemotherapy drugs induce pyroptosis through caspase-3 cleavage of a gasdermin. Nature. 2017; 547(7661)

13. Fang X, Wang H, Han D, Xie E, Yang X, Wei J, Gu S, Gao F, Zhu N, Yin X: Ferroptosis as a target for protection against cardiomyopathy. Proc Natl Acad Sci USA. 2019; 116(7):2672-2680.

14. Wang Q, Yang Y, Fu X, Wang Z, Liu Y, Li M, Zhang Y, Li Y, Li P-F, Yu T et al: Long noncoding RNA XXYLT1-AS2 regulates proliferation and adhesion by targeting the RNA binding protein FUS in HUVEC. Atherosclerosis. 2020; 298:58-69.

15. Liu Y, Yang Y, Wang Z, Fu X, Chu X-M, Li Y, Wang Q, He X, Li M, Wang K et al: Insights into the regulatory role of circRNA in angiogenesis and clinical implications. Atherosclerosis. 2020; 298:14-26.

16. Tang N, Jiang S, Yang Y, Liu S, Ponnusamy M, Xin H, Yu T: Noncoding RNAs as therapeutic targets in atherosclerosis with diabetes mellitus. Cardiovasc Ther. 2018; 36(4):e12436.

17. Yang $\mathrm{Y}, \mathrm{Yu} \mathrm{T}$, Jiang S, Zhang $\mathrm{Y}, \mathrm{Li} \mathrm{M}$, Tang N, Ponnusamy M, Wang J-X, Li P-F: miRNAs as potential therapeutic targets and diagnostic biomarkers for cardiovascular disease with a particular focus on WO2010091204. Expert Opin Ther Pat. 2017; 27(9):1021-1029.

18. Liu S, Yang Y, Jiang S, Tang N, Tian J, Ponnusamy M, Tariq MA, Lian Z, Xin H, Yu T: Understanding the role of non-coding RNA (ncRNA) in stent restenosis. Atherosclerosis. 2018; 272:153-161.

19. Cheng M, Yang Y, Xin H, Li M, Zong T, He X, Yu T, Xin H: Non-coding RNAs in aortic dissection: From biomarkers to therapeutic targets. J Cell Mol Med. 2020; 24(20):11622-11637.

20. Liu S, Yang $\mathrm{Y}$, Jiang $\mathrm{S}$, Xu H, Tang N, Lobo A, Zhang R, Liu S, Yu T, Xin H: MiR-378a-5p Regulates Proliferation and Migration in Vascular Smooth Muscle Cell by Targeting CDK1. Front Genet. 2019; 10:22.

21. He X, Lian Z, Yang Y, Wang Z, Fu X, Liu Y, Li M, Tian J, Yu T, Xin H: Long Non-coding RNA PEBP1P2 Suppresses Proliferative VSMCs Phenotypic Switching and Proliferation in Atherosclerosis. Mol Ther Nucleic Acids. 2020; 22:84-98.

22. Song $\mathrm{L}$, Qiao $\mathrm{G}, \mathrm{Xu}$ Y, Ma $\mathrm{L}$, Jiang $\mathrm{W}$ : Role of non-coding RNAs in cardiotoxicity of chemotherapy. Surg Oncol .2018; 27(3):526-538.

23. Rahman AM, Yusuf SW, Ewer MS: Anthracycline-induced cardiotoxicity and the cardiac-sparing effect of liposomal formulation. Int J Nanomedicine. 2007; 2(4):567-583

24. Zheng K, Li R, Zhou X, Hu P, Zhang Y, Huang Y, Chen Z, Huang M: Dual actions of albumin packaging and tumor targeting enhance the antitumor efficacy and reduce the cardiotoxicity of doxorubicin in vivo. Int $\mathrm{J}$ Nanomedicine. 2015; 10:5327-5342.

25. Zhang D, Xu Q, Wang N, Yang Y, Liu J, Yu G, Yang X, Xu H, Wang H: A complex micellar system co-delivering curcumin with doxorubicin against cardiotoxicity and tumor growth. Int J Nanomedicine. 2018; 13:4549-4561.

26. Fang Y, Wang H, Dou H-J, Fan X, Fei X-C, Wang L, Cheng S, Janin A, Wang L, Zhao W-L: Doxorubicin-loaded dextran-based nano-carriers for highly efficient inhibition of lymphoma cell growth and synchronous reduction of cardiac toxicity. Int J Nanomedicine. 2018; 13:5673-5683.

27. Lebrecht D, Geist A, Ketelsen UP, Haberstroh J, Setzer B, Walker UA: Dexrazoxane prevents doxorubicin-induced long-term cardiotoxicity and protects myocardial mitochondria from genetic and functional lesions in rats. Br J Pharmacol. 2007; 151(6):771-778.

28. Keller S, Ridinger J, Rupp A-K, Janssen JWG, Altevogt P: Body fluid derived exosomes as a novel template for clinical diagnostics. J Transl Med. 2011, 9:86.

29. Raposo G, Stahl PD: Extracellular vesicles: a new communication paradigm? Nat Rev Mol Cell Biol.2019; 20(9):509-510.

30. Tkach M, Théry C: Communication by Extracellular Vesicles: Where We Are and Where We Need to Go. Cell. 2016; 164(6):1226-1232.

31. Zhang Y, Hu YW, Zheng L, Wang Q: Characteristics and Roles of Exosomes in Cardiovascular Disease. DNA and cell biology. 2017; 36(3):202-211.

32. Skog J, Würdinger T, van Rijn S, Meijer DH, Gainche L, Sena-Esteves M, Curry WT, Jr., Carter BS, Krichevsky AM, Breakefield XO: Glioblastoma microvesicles transport RNA and proteins that promote tumour growth and provide diagnostic biomarkers. Nature cell biology. 2008; 10(12):1470-1476.

33. Kulshreshtha A, Ahmad T, Agrawal A, Ghosh B: Proinflammatory role of epithelial cell-derived exosomes in allergic airway inflammation. The Journal of allergy and clinical immunology. 2013; 131(4):1194-1203, 1203.e1191-1114.

34. van Niel G, D'Angelo G, Raposo G: Shedding light on the cell biology of extracellular vesicles. Nat Rev Mol Cell Biol.2018; 19(4):213-228.

35. Barile L, Moccetti T, Marbán E, Vassalli G: Roles of exosomes in cardioprotection. Eur Heart J. 2017; 38(18):1372-1379.

36. Lässer C, Alikhani VS, Ekström K, Eldh M, Paredes PT, Bossios A, Sjöstrand M, Gabrielsson S, Lötvall J, Valadi H: Human saliva, plasma and breast milk exosomes contain RNA: uptake by macrophages. J Transl Med. 2011; 9:9.

37. Street JM, Barran PE, Mackay CL, Weidt S, Balmforth C, Walsh TS, Chalmers RTA, Webb DJ, Dear JW: Identification and proteomic profiling of exosomes in human cerebrospinal fluid. J Transl Med. 2012; 10:5.

38. Kalluri R, LeBleu VS: The biology, function, and biomedical applications of exosomes. Science (New York, NY). 2020; 367(6478).

39. Valadi H, Ekström K, Bossios A, Sjöstrand M, Lee JJ, Lötvall JO: Exosome-mediated transfer of mRNAs and microRNAs is a novel mechanism of genetic exchange between cells. Nat Cell Biol. 2007; 9(6):654-659.

40. Dou Y, Cha DJ, Franklin JL, Higginbotham JN, Jeppesen DK, Weaver AM, Prasad N, Levy S, Coffey RJ, Patton JG et al: Circular RNAs are down-regulated in KRAS mutant colon cancer cells and can be transferred to exosomes. Sci Rep. 2016; 6:37982.

41. Gezer U, Özgür E, Cetinkaya M, Isin M, Dalay N: Long non-coding RNAs with low expression levels in cells are enriched in secreted exosomes. Cell Biol Int. 2014; 38(9):1076-1079.

42. Yuan T, Huang X, Woodcock M, Du M, Dittmar R, Wang Y, Tsai S, Kohli M, Boardman L, Patel T et al: Plasma extracellular RNA profiles in healthy and cancer patients. Sci Rep. 2016; 6:19413

43. Thakur BK, Zhang H, Becker A, Matei I, Huang Y, Costa-Silva B, Zheng Y, Hoshino A, Brazier H, Xiang J et al: Double-stranded DNA in exosomes: a novel biomarker in cancer detection. Cell Res. 2014; 24(6):766-769.

44. Zhu L, Li J, Gong Y, Wu Q, Tan S, Sun D, Xu X, Zuo Y, Zhao Y, Wei Y-Q et al: Exosomal tRNA-derived small RNA as a promising biomarker for cancer diagnosis. Mol Cancer. 2019; 18(1):74

45. Li M, Yang Y, Wang Z, Zong T, Fu X, Aung LHH, Wang K, Wang J-X, Yu T: Piwi-interacting RNAs (piRNAs) as potential biomarkers and therapeutic targets for cardiovascular diseases. Angiogenesis. 2020

46. Laulagnier K, Vincent-Schneider H, Hamdi S, Subra C, Lankar D, Record M: Characterization of exosome subpopulations from RBL-2H3 cells using fluorescent lipids. Blood Cells Mol Dis. 2005; 35(2):116-121.

47. Subra C, Laulagnier K, Perret B, Record M: Exosome lipidomics unravels lipid sorting at the level of multivesicular bodies. Biochimie. 2007; 89(2):205-212.

48. Steinherz LJ, Graham T, Hurwitz R, Sondheimer HM, Schwartz RG, Shaffer EM, Sandor G, Benson L, Williams R: Guidelines for cardiac monitoring of children during and after anthracycline therapy: report of the Cardiology Committee of the Childrens Cancer Study Group. Pediatrics. 1992; 89(5 Pt 1):942-949.

49. Meinardi MT, van der Graaf WT, van Veldhuisen DJ, Gietema JA, de Vries EG, Sleijfer DT: Detection of anthracycline-induced cardiotoxicity. Cancer Treat Rev. 1999; 25(4):237-247.

50. Galán-Arriola C, Lobo M, Vílchez-Tschischke JP, López GJ, de Molina-Iracheta A, Pérez-Martínez C, Agüero J, Fernández-Jiménez R, Martín-García A, Oliver E et al: Serial Magnetic Resonance Imaging to Identify Early Stages of Anthracycline-Induced Cardiotoxicity. J Am Coll Cardiol. 2019· 73(7):779-791.

51. de Geus-Oei L-F, Mavinkurve-Groothuis AMC, Bellersen L, Gotthardt M, Oyen WJG, Kapusta L, van Laarhoven HWM: Scintigraphic techniques for early detection of cancer treatment-induced cardiotoxicity. J Nucl Med. 2011; 52(4):560-571.

52. Iles L, Pfluger H, Phrommintikul A, Cherayath J, Aksit P, Gupta SN, Kaye DM, Taylor AJ: Evaluation of diffuse myocardial fibrosis in heart failure with 
cardiac magnetic resonance contrast-enhanced T1 mapping. J Am Coll Cardiol. 2008; 52(19):1574-1580

53. Ugander M, Oki AJ, Hsu L-Y, Kellman P, Greiser A, Aletras AH, Sibley CT, Chen MY, Bandettini WP, Arai AE: Extracellular volume imaging by magnetic resonance imaging provides insights into overt and sub-clinical myocardial pathology. Eur Heart J. 2012; 33(10):1268-1278.

54. Neilan TG, Coelho-Filho OR, Shah RV, Feng JH, Pena-Herrera D, Mandry D, Pierre-Mongeon F, Heydari B, Francis SA, Moslehi J et al: Myocardial extracellular volume by cardiac magnetic resonance imaging in patients treated with anthracycline-based chemotherapy. Am J Cardiol. 2013; 111(5):717-722.

55. Alpert JS, Thygesen K, Antman E, Bassand JP: Myocardial infarction redefined--a consensus document of The Joint European Society of Cardiology/American College of Cardiology Committee for the redefinition of myocardial infarction. J Am Coll Cardiol. 2000; 36(3):959-969.

56. Panteghini M: Role and importance of biochemical markers in clinical cardiology. Eur Heart J. 2004; 25(14):1187-1196.

57. Cardinale D, Colombo A, Torrisi R, Sandri MT, Civelli M, Salvatici M, Lamantia G, Colombo N, Cortinovis S, Dessanai MA et al: Trastuzumab-induced cardiotoxicity: clinical and prognostic implications of troponin I evaluation. J Clin Oncol. 2010; 28(25):3910-3916

58. Morris PG, Chen C, Steingart R, Fleisher M, Lin N, Moy B, Come S, Sugarman $\mathrm{S}$, Abbruzzi A, Lehman $\mathrm{R}$ et al: Troponin I and C-reactive protein are commonly detected in patients with breast cancer treated with dose-dense chemotherapy incorporating trastuzumab and lapatinib. Clin Cancer Res. 2011; 17(10):3490-3499

59. Schmidinger M, Zielinski CC, Vogl UM, Bojic A, Bojic M, Schukro C, Ruhsam $\mathrm{M}$, Hejna $\mathrm{M}$, Schmidinger $\mathrm{H}$ : Cardiac toxicity of sunitinib and sorafenib in patients with metastatic renal cell carcinoma. J Clin Oncol. 2008; 26(32):5204-5212.

60. Chen S, Garami M, Gardner DG: Doxorubicin selectively inhibits brain versus atrial natriuretic peptide gene expression in cultured neonatal rat myocytes. Hypertension. 1999; 34(6):1223-1231.

61. Feola M, Garrone O, Occelli M, Francini A, Biggi A, Visconti G, Albrile F, Bobbio M, Merlano M: Cardiotoxicity after anthracycline chemotherapy in breast carcinoma: effects on left ventricular ejection fraction, troponin I and brain natriuretic peptide. Int J Cardiol. 2011; 148(2):194-198.

62. Lee HS, Son CB, Shin SH, Kim YS: Clinical correlation between brain natriutetic peptide and anthracyclin-induced cardiac toxicity. Cancer Res Treat. 2008; 40(3):121-126

63. Ruggeri C, Gioffré S, Achilli F, Colombo GI, D'Alessandra Y: Role of microRNAs in doxorubicin-induced cardiotoxicity: an overview of preclinical models and cancer patients. Heart Fail Rev. 2018; 23(1):109-122.

64. Beaumier A, Robinson SR, Robinson N, Lopez KE, Meola DM, Barber LG, Bulmer BJ, Calvalido J, Rush JE, Yeri A et al: Extracellular vesicular microRNAs as potential biomarker for early detection of doxorubicin-induced cardiotoxicity. J Vet Intern Med. 2020; 34(3):1260-1271.

65. Melo SA, Luecke LB, Kahlert C, Fernandez AF, Gammon ST, Kaye J, LeBleu VS, Mittendorf EA, Weitz J, Rahbari N et al: Glypican-1 identifies cancer exosomes and detects early pancreatic cancer. Nature. 2015; 523(7559):177-182.

66. Niu L, Song X, Wang N, Xue L, Song X, Xie L: Tumor-derived exosomal proteins as diagnostic biomarkers in non-small cell lung cancer. Cancer Sci. 2019; 110(1):433-442.

67. Fu H, Yang H, Zhang X, Wang B, Mao J, Li X, Wang M, Zhang B, Sun Z, Qian $\mathrm{H}$ et al: Exosomal TRIM3 is a novel marker and therapy target for gastric cancer. J Exp Clin Cancer Res. 2018; 37(1):162.

68. Yarana C, Carroll D, Chen J, Chaiswing L, Zhao Y, Noel T, Alstott M, Bae Y, Dressler EV, Moscow JA et al: Extracellular Vesicles Released by Cardiomyocytes in a Doxorubicin-Induced Cardiac Injury Mouse Model Contain Protein Biomarkers of Early Cardiac Injury. Clin Cancer Res. 2018; 24(7):1644-1653

69. Dargani ZT, Singla DK: Embryonic stem cell-derived exosomes inhibit doxorubicin-induced TLR4-NLRP3-mediated cell death-pyroptosis. AM J PHYSIOL-HEART C. 2019; 1:317(312)

70. Singla DK, Johnson TA, Tavakoli Dargani Z: Exosome Treatment Enhances Anti-Inflammatory M2 Macrophages and Reduces Inflammation-Induced Pyroptosis in Doxorubicin-Induced Cardiomyopathy. Cells. 2019; 8(10).

71. Xia W, Chen $\mathrm{H}$, Xie C, Hou M: Long-noncoding RNA MALAT1 sponges microRNA-92a-3 $p$ to inhibit doxorubicin-induced cardiac senescence by targeting ATG4a. Aging (Albany NY. 2020; 12(9):8241-8260.

72. Milano G, Biemmi V, Lazzarini E, Balbi C, Ciullo A, Bolis S, Ameri P, Di Silvestre D, Mauri P, Barile L et al: Intravenous administration of cardiac progenitor cell-derived exosomes protects against doxorubicin/trastuzumab-induced cardiac toxicity. Cardiovasc Res. 2020; 116(2):383-392

73. Qiao L, Hu S, Huang K, Su T, Li Z, Vandergriff A, Cores J, Dinh P-U, Allen T, Shen $\mathrm{D}$ et al: Tumor cell-derived exosomes home to their cells of origin and can be used as Trojan horses to deliver cancer drugs. Theranostics. 2020; 10(8):3474-3487.

74. Tian Y, Li S, Song J, Ji T, Zhu M, Anderson GJ, Wei J, Nie G: A doxorubicin delivery platform using engineered natural membrane vesicle exosomes for targeted tumor therapy. Biomaterials. 2014; 35(7):2383-2390.

75. Phung CD, Pham TT, Nguyen HT, Nouyen TT, Ou W, Jeong J-H, Choi H-G, Ku SK, Yong CS, Kim JO: Anti-CTLA-4 Antibody-Functionalized Dendritic
Cell-derived Exosomes Targeting Tumor-draining Lymph Nodes for Effective Induction of Antitumor T-cell Responses. Acta biomaterialia. 2020.

76. Ibrahim AG-E, Cheng K, Marbán E: Exosomes as critical agents of cardiac regeneration triggered by cell therapy. Stem Cell Reports. 2014; 2(5):606-619.

77. Barile L, Lionetti V, Cervio E, Matteucci M, Gherghiceanu M, Popescu LM, Torre T, Siclari F, Moccetti T, Vassalli G: Extracellular vesicles from human cardiac progenitor cells inhibit cardiomyocyte apoptosis and improve cardiac function after myocardial infarction. Cardiovasc Res. 2014; 103(4):530-541.

78. Bai B, Yang Y, Wang Q, Li M, Tian C, Liu Y, Aung LHH, Li P-F, Yu T, Chu X-M: NLRP3 inflammasome in endothelial dysfunction. Cell Death Dis. 2020; 11(9):776

79. Horwitz EM, Gordon PL, Koo WKK, Marx JC, Neel MD, McNall RY, Muul L, Hofmann T: Isolated allogeneic bone marrow-derived mesenchymal cells ngraft and stimulate growth in children with osteogenesis imperfecta: Implications for cell therapy of bone. Proc Natl Acad Sci U S A. 2002; 99(13):8932-8937.

80. Lou G, Chen Z, Zheng M, Liu Y: Mesenchymal stem cell-derived exosomes as a new therapeutic strategy for liver diseases. Exp Mol Med. 2017; 49(6):e346.

81. Zhang ZX, Guan LX, Zhang K, Zhang Q, Dai LJ: A combined procedure to deliver autologous mesenchymal stromal cells to patients with traumatic brain injury. Cytotherapy.2008; 10(2):134-139.

82. De Keyser J: Autologous mesenchymal stem cell transplantation in stroke patients. Ann Neurol. 2005; 58(4)

83. Xu W, Zhang X, Qian H, Zhu W, Sun X, Hu J, Zhou H, Chen Y: Mesenchymal stem cells from adult human bone marrow differentiate into a cardiomyocyte phenotype in vitro. Exp Biol Med (Maywood). 2004; 229(7):623-631.

84. Katritsis DG, Sotiropoulou PA, Karvouni E, Karabinos I, Korovesis S, Perez SA, Voridis EM, Papamichail M: Transcoronary transplantation of autologous mesenchymal stem cells and endothelial progenitors into infarcted human myocardium. Catheter Cardiovasc Interv. 2005; 65(3):321-329.

85. Ammar HI, Sequiera GL, Nashed MB, Ammar RI, Gabr HM, Elsayed HE, Sareen N, Rub EA-E, Zickri MB, Dhingra S: Comparison of adipose tissue- and bone marrow- derived mesenchymal stem cells for alleviating doxorubicin-induced cardiac dysfunction in diabetic rats. Stem Cell Res Ther. 2015; 6:148.

86. Wan Z, Zhao L, Lu F, Gao X, Dong Y, Zhao Y, Wei M, Yang G, Xing C, Liu L: Mononuclear phagocyte system blockade improves therapeutic exosome delivery to the myocardium. Theranostics. 2020; 10(1):218-230.

87. Zhang L, Yu D: Exosomes in cancer development, metastasis, and immunity. Biochim Biophys Acta Rev Cancer. 2019; 1871(2):455-468.

88. Liu H, Gao W, Yuan J, Wu C, Yao K, Zhang L, Ma L, Zhu J, Zou Y, Ge J: Exosomes derived from dendritic cells improve cardiac function via activation of CD4(+) T lymphocytes after myocardial infarction. J MOL CELL CARDIOL. 2016; 91(123):33.

89. Gao W, Liu H, Yuan J, Wu C, Huang D, Ma Y, Zhu J, Ma L, Guo J, Shi H et al: Exosomes derived from mature dendritic cells increase endothelial inflammation and atherosclerosis via membrane TNF- $\alpha$ mediated NF- $\mathrm{KB}$ pathway. J Cell Mol Med. 2016; 20(12):2318-2327.

90. Obregon C, Rothen-Rutishauser B, Gerber P, Gehr P, Nicod LP: Active uptake of dendritic cell-derived exovesicles by epithelial cells induces the release of inflammatory mediators through a TNF-alpha-mediated pathway. Am J Pathol. 2009; 175(2):696-705.

91. Shi S, Rao Q, Zhang C, Zhang X, Qin Y, Niu Z: Dendritic Cells Pulsed with Exosomes in Combination with PD-1 Antibody Increase the Efficacy of Sorafenib in Hepatocellular Carcinoma Model. Transl Oncol. 2018; 11(2):250-258.

92. Chen S, Lv M, Fang S, Ye W, Gao Y, Xu Y: Poly(I:C) enhanced anti-cervical cancer immunities induced by dendritic cells-derived exosomes. Int J Biol Macromol. 2018; 113:1182-1187.

93. Pitt JM, Charrier M, Viaud S, André F, Besse B, Chaput N, Zitvogel L: Dendritic cell-derived exosomes as immunotherapies in the fight against cancer. J Immunol. 2014; 193(3):1006-1011.

94. Yin W, Ouyang S, Luo Z, Zeng Q, Hu B, Xu L, Li Y, Xiao B, Yang H: Immature Exosomes Derived from MicroRNA-146a Overexpressing Dendritic Cells Act as Antigen-Specific Therapy for Myasthenia Gravis. Inflammation. 2017; 40(4):1460-1473.

95. Liu Q, Rojas-Canales DM, Divito SJ, Shufesky WJ, Stolz DB, Erdos G, Sullivan MLG, Gibson GA, Watkins SC, Larregina AT et al: Donor dendritic cell-derived exosomes promote allograft-targeting immune response. J Clin Invest. 2016; 126(8):2805-2820.

96. Schindler C, Collinson A, Matthews C, Pointon A, Jenkinson L, Minter RR, Vaughan TJ, Tigue NJ: Exosomal delivery of doxorubicin enables rapid cell entry and enhanced in vitro potency. PLoS ONE.2019; 14(3):e0214545.

97. Kanchanapally R, Deshmukh SK, Chavva SR, Tyagi N, Srivastava SK, Patel GK, Singh AP, Singh S: Drug-loaded exosomal preparations from different cell types exhibit distinctive loading capability, yield, and antitumor efficacies: a comparative analysis. Int J Nanomedicine. 2019; 14:531-541.

98. Toffoli G, Hadla M, Corona G, Caligiuri I, Palazzolo S, Semeraro S, Gamini A, Canzonieri V, Rizzolio F: Exosomal doxorubicin reduces the cardiac toxicity of doxorubicin. Nanomedicine (Lond). 2015; 10(19):2963-2971.

99. Hadla M, Palazzolo S, Corona G, Caligiuri I, Canzonieri V, Toffoli G, Rizzolio F: Exosomes increase the therapeutic index of doxorubicin in breast and ovarian cancer mouse models. Nanomedicine (Lond). 2016,; 11(18):2431-2441. 
100. Lee Y, Ahn C, Han J, Choi H, Kim J, Yim J, Lee J, Provost P, Rådmark O, Kim S et al: The nuclear RNase III Drosha initiates microRNA processing. Nature. 2003; 425(6956):415-419.

101. Basson M: MicroRNAs loom large in the heart. Nat Med. 2007; 13(5):541.

102. Thum T, Galuppo P, Wolf C, Fiedler J, Kneitz S, van Laake LW, Doevendans PA, Mummery CL, Borlak J, Haverich A et al: MicroRNAs in the human heart: a clue to fetal gene reprogramming in heart failure. Circulation. 2007, ;116(3):258-267.

103. Chien KR: Molecular medicine: microRNAs and the tell-tale heart. Nature. 2007; 447(7143):389-390.

104. Gupta SK, Garg A, Avramopoulos P, Engelhardt S, Streckfuss-Bömeke K, Batkai S, Thum T: miR-212/132 Cluster Modulation Prevents Doxorubicin-Mediated Atrophy and Cardiotoxicity. Mol Ther. 2019; 27(1):17-28.

105. Bang C, Batkai S, Dangwal S, Gupta SK, Foinquinos A, Holzmann A, Just A, Remke J, Zimmer K, Zeug A et al: Cardiac fibroblast-derived microRNA passenger strand-enriched exosomes mediate cardiomyocyte hypertrophy. J Clin Invest. 2014; 124(5):2136-2146.

106. Deng Z, Rong Y, Teng Y, Zhuang X, Samykutty A, Mu J, Zhang L, Cao P, Yan $\mathrm{J}$, Miller D et al: Exosomes miR-126a released from MDSC induced by DOX treatment promotes lung metastasis. Oncogene. 2017; 36(5):639-651.

107. Gong C, Tian J, Wang Z, Gao Y, Wu X, Ding X, Qiang L, Li G, Han Z, Yuan Y et al: Functional exosome-mediated co-delivery of doxorubicin and hydrophobically modified microRNA 159 for triple-negative breast cancer therapy. Journal of nanobiotechnology. 2019; 17(1):93.

108. Lou G, Chen L, Xia C, Wang W, Qi J, Li A, Zhao L, Chen Z, Zheng M, Liu Y: MiR-199a-modified exosomes from adipose tissue-derived mesenchymal stem cells improve hepatocellular carcinoma chemosensitivity through mTOR pathway. Journal of experimental \& clinical cancer research : CR. 2020; 39(1):4.

109. Li Y, Liang Y, Sang Y, Song X, Zhang H, Liu Y, Jiang L, Yang Q: MiR-770 suppresses the chemo-resistance and metastasis of triple negative breast cancer via direct targeting of STMN1. Cell Death Dis. 2018; 9(1):14.

110. Liu X, Lu Y, Xu Y, Hou S, Huang J, Wang B, Zhao J, Xia S, Fan S, Yu X et al: Exosomal transfer of miR-501 confers doxorubicin resistance and tumorigenesis via targeting of BLID in gastric cancer. Cancer letters. 2019; 459:122-134.

111. Ponnusamy M, Liu F, Zhang Y-H, Li R-B, Zhai M, Liu F, Zhou L-Y, Liu C-Y, Yan K-W, Dong Y-H et al: Long Noncoding RNA CPR (Cardiomyocyte Proliferation Regulator) Regulates Cardiomyocyte Proliferation and Cardiac Repair. Circulation. 2019; 139(23):2668-2684.

112. Xie Z, Xia W, Hou M: Long intergenic non-coding RNA-p21 mediates cardiac senescence via the $\mathrm{Wnt} / \beta$-catenin signaling pathway in doxorubicin-induced cardiotoxicity. Mol Med Re. 2018; 17(2):2695-2704.

113. Wang X, Pei X, Guo G, Qian X, Dou D, Zhang Z, Xu X, Duan X: Exosome-mediated transfer of long noncoding RNA H19 induces doxorubicin resistance in breast cancer. J Cell Physiol, 2020; 235(10):6896-6904.

114. Soares AR, Martins-Marques T, Ribeiro-Rodrigues T, Ferreira JV, Catarino S, Pinho MJ, Zuzarte M, Isabel Anjo S, Manadas B, P G Sluijter J et al: Gap junctional protein $\mathrm{C} \times 43$ is involved in the communication between extracellular vesicles and mammalian cells. Sci Re. 2015; 5:13243.

115. Lian S, Xie X, Lu Y, Jia L: Checkpoint CD47 Function On Tumor Metastasis And Immune Therapy. OncoTargets and therapy. 2019; 12:9105-9114.

116. Koh E, Lee EJ, Nam GH, Hong Y, Cho E, Yang Y, Kim IS: Exosome-SIRPa, a CD47 blockade increases cancer cell phagocytosis. Biomaterials. 2017; 121:121-129.

117. Zhuang J, Tan J, Wu C, Zhang J, Liu T, Fan C, Li J, Zhang Y: Extracellular vesicles engineered with valency-controlled DNA nanostructures deliver CRISPR/Cas9 system for gene therapy. Nucleic acids research. 2020.

118. Moon J, Lim J, Lee S, Son HY, Rho HW, Kim H, Kang H, Jeong J, Lim E-K, Jung $\mathrm{J}$ et al: Urinary exosomal mRNA detection using novel isothermal gene amplification method based on three-way junction. Biosens Bioelectron. 2020; 167:112474.

119. Timothy N Tiambeng, David S Roberts, Kyle A Brown, Yanlong Zhu, Bifan Chen, Zijie Wu, Stanford D Mitchell, M Guardado-Alvarez, Song Jin, Ge Y: Nanoproteomics enables proteoform-resolved analysis of low-abundance proteins in human serum. Nat Commun. 2020; 11(1):3903. 